\title{
Are D-Neurons and Trace Amine-Associated Receptor, Type 1 Involved in Mesolimbic Dopamine Hyperactivity of Schizophrenia?
}

\section{Keiko Ikemoto*}

Department of Neuropsychiatry, Fukushima Medical University, School of Medicine, Fukushima 960-1295, Japan

Department of Psychiatry, Iwaki Kyoritsu General Hospital, Iwaki 973-8555, Japan

\begin{abstract}
Although dopamine (DA) dysfunction is a well-known hypothesis for etiology of schizophrenia, molecular basis of mesolimbic DA hyperactivity has not yet been clarified. To explain this, modulating function of trace amines on DA neurotransmission and the decreased number of striatal D-neurons, trace amine-producing neurons, were considered. Notably, Trace Amine-Associated Receptor, Type 1 (TAAR1), a subtype of trace amine receptors, has a large number of ligands, including tyramine, $\beta$-phenylethylamine and methamphetamine that influence on human mental state, and is now regarded as a target receptor for novel neuroleptics. Reduced stimulation of TAAR1 on DA neurons in the midbrain ventral tegmental area (VTA) has been revealed to increase firing frequency of VTA DA neurons. The author and her colleagues reported the decrease of D-neurons in the striatum and nucleus accumbens of postmortem brains of patients with schizophrenia. This may imply the decrease of trace amine synthesis and consequent reduction of the stimulation of TAAR1 on terminals of midbrain VTA DA neurons, and may lead to mesolimbic DA hyperactivity in schizophrenia. The decrease of striatal D-neurons of postmortem brains of schizophrenia might be due to neural stem cell dysfunction in the subventricular zone of lateral ventricle. The new "D-cell hypothesis", in which D-neurons and TAAR1 are involved, may explain mesolimbic DA hyperactivity of schizophrenia.
\end{abstract}

Keywords: Dopamine; D-neuron; Ventral tegmental area; Schizophrenia; TAAR1

\section{Introduction}

Dopamine (DA) dysfunction [1,2], glutamate dysfunction $[3,4]$, neurodevelopmental deficits $[5,6]$, or neural stem cell dysfunction $[7,8]$ are well-known hypotheses for etiology of schizophrenia. DA dysfunction hypothesis suggested that mesolimbic DA hyperactivity caused positive symptoms such as paranoid-hallucinatory state of schizophrenia [1,2]. It is also explained by the efficacy of DA D2 blockers for paranoid-hallucinatory state and also by hallucinogenic acts of DA stimulants including methamphetamine or amphetamine $[1,2]$. Glutamate dysfunction theory was induced by the fact that intake of phencyclidine (CPC), an antagonist of NMDA receptor, produces equivalent to negative symptoms of schizophrenia, such as withdrawal or flattened affect, as well as positive symptoms [3,4]. The neurodevelopmental deficits hypothesis implicates that schizophrenia is the consequence of prenatal abnormalities resulting from the interaction of genetic and environmental factors $[5,6]$. Neural stem cell dysfunction has also been shown to be a cause of schizophrenia $[7,8]$.

Although mesolimbic DA hyperactivity $[1,2]$ has been well documented in pathogenesis of schizophrenia, the molecular basis of this mechanism has not yet been detailed. In the present article, the author hypothesized the involvement of striatal D-neurons and trace amine-associated receptor, type 1 (TAAR1) in the pathogenesis of mesolimbic DA hyperactivity of schizophrenia [9]

\section{D-neuron}

The "D-cell" was described, by Jaeger et al. [10], in 1983 in the rat central nervous system and was defined "the non-monoaminergic aromatic L-amino acid decarboxylase (AADC)-containing cell” [10]. The D-cell contains AADC but not dopaminergic nor serotonergic [10]. D-cells produce trace amines $[11,12]$, and may also act as an APUD (amine precursor uptake and decarboxylation) system that takes up amine precursors and transforms them to amines by decarboxylation [13]. The localizations of D-cells were specified into 14 groups, from D1 (the spinal cord) to D14 (the bed nucleus of stria terminalis) in caudo-rostral orders of the rat central nervous system using AADC immunohistochemistry $[14,15]$. In this usage, the classification term "D" means decarboxylation. In rodents $[13,16,17]$, a small number of D-cells in the striatum were rostrally described and confirmed to be neurons by electron-microscopic observation [13].

I reported in 1997, "dopa-decarboxylating neurons specific to the human striatum [18-21]", that is, "D-neurons" in the human striatum [20,22] (classified to be D15) [20], and later, the reduction of the number of D-neurons in the striatum and nucleus accumbens of patients with schizophrenia $[9,22]$.

\section{Trace Amine-Associated Receptor, Type 1 (TAAR1)}

Cloning of trace amine receptors in 2001 [23,24], elicited enormous efforts for exploring signal transduction of these G-protein coupled receptors whose genes are located on chromosome focus 6q23.1 [25]. The receptors have been shown to co-localize with dopamine or adrenaline transporters in monoamine neurons and to modulate the functions of monoamines [26-28].

The trace amine-associated receptor, type 1 (TAAR1) having a large number of ligands, including tyramine, $\beta$-phenylethylamine (PEA) and psychostimulants, for example methamphetamine, 3,4-methylenedioxymethamphetamine (MDMA) and lysergic acid diethylamide (LSD) $[23,25,29]$, has become a target receptor for exploring novel neuroleptics [30,31]. TAAR1 knockout mice showed schizophrenia-like behaviors with a deficit in prepulse inhibition [32]. TAAR1 knockout mice showed greater locomotor response to

*Corresponding author: Keiko Ikemoto, MD, PhD, Department of Neuropsychiatry, Fukushima Medical University, School of Medicine, 1 Hikarigaoka, Fukushima 9601295, Japan, Tel: +81-24-547-1331; Fax: +81-24-548-6735; E-mail: ikemoto@fmu.ac.jp

Received February 24, 2012; Accepted March 21, 2012; Published March 22, 2012

Citation: Ikemoto K (2012) Are D-Neurons and Trace Amine-Associated Receptor, Type 1 Involved in Mesolimbic Dopamine Hyperactivity of Schizophrenia? Med chem 2: 038-040. doi:10.4172/2161-0444.1000111

Copyright: (C) 2012 Ikemoto K. This is an open-access article distributed under the terms of the Creative Commons Attribution License, which permits unrestricted use, distribution, and reproduction in any medium, provided the original author and source are credited. 
Citation: Ikemoto K (2012) Are D-Neurons and Trace Amine-Associated Receptor, Type 1 Involved in Mesolimbic Dopamine Hyperactivity of Schizophrenia? Med chem 2: 038-040. doi:10.4172/2161-0444.1000111

amphetamine and released more DA (and noradrenaline) in response to amphetamine than wild type mice [32]. It has been shown that TAAR1 has a thermoregulatory function [33]. It was clarified that increased stimulation of TAAR1 receptors on cell membranes of DA neurons in the midbrain ventral tegmental area (VTA) reduced firing frequency of VTA DA neurons [30-32].

\section{A New "D-Cell Hypothesis" of Schizophrenia}

My own new theory, "D-cell hypothesis", for explaining mesolimbic DA hyperactivity in pathogenesis of schizophrenia is shown in Figure 1. In brains of patients with schizophrenia, dysfunction of neural stem cells in the subventricular zone of lateral ventricle may cause the decrease of $\mathrm{D}$-neurons in the striatum and nucleus accumbens [8,34]. This may lead to the decrease of the amounts of trace amines in the nuclei, though direct evidences have not yet been demonstrated. Enlargement of the lateral ventricle [35,36], a usual finding documented in brain imaging studies of schizophrenia, might also be due to dysfunction of neural stem cells of the subventricular zone $[7,8]$.

The reduction of TAAR1 stimulation on DA terminals of VTA DA neurons, caused by putative decrease of striatal trace amine synthesis, may increase the firing frequency of VTA DA neurons $[30,32]$. This may lead to the increase of DA release in the nucleus accumbens, that is, mesolimbic DA hyperactivity. It has been shown that D2 stimulation of neural stem cells in the striatum inhibited forebrain neural stem cell proliferation [37]. Then, striatal DA hyperactivity may lead to additional decrease of $\mathrm{D}$-neurons, which might induce additional hyperactivity of mesolimbic DA system. Actions of D2 blocking agents in pharmacotherapy of schizophrenia might partially be explained by the decrease of inhibition to forebrain neural stem cell proliferations. It might be consistent with the clinical evidences that D2 blockers are effective for the treatment of schizophrenia.

\section{Conclusion}

The D-neuron, i.e., the trace amine-producing neuron, and TAAR1 might be a clue for pathogenesis of DA hyperactivity of schizophrenia. Further exploration of signal transduction of the D-neuron is essential.

\section{Acknowledgement}

The present study was supported by Grant-in-Aid for Scientific Research from Japan Society for the Promotion of Science (C-22591265).

\section{References}

1. Hokfelt T, Ljungdahl A, Fuxe K, Johansson O (1974) Dopamine nerve terminals in the rat limbic cortex: aspects of the dopamine hypothesis of schizophrenia. Science 184: 177-179.

2. Toru M, Nishikawa T, Mataga N, Takashima N (1982) Dopamine metabolism increases in post-mortem schizophrenic basal ganglia. J Neural Transm 54 $181-191$

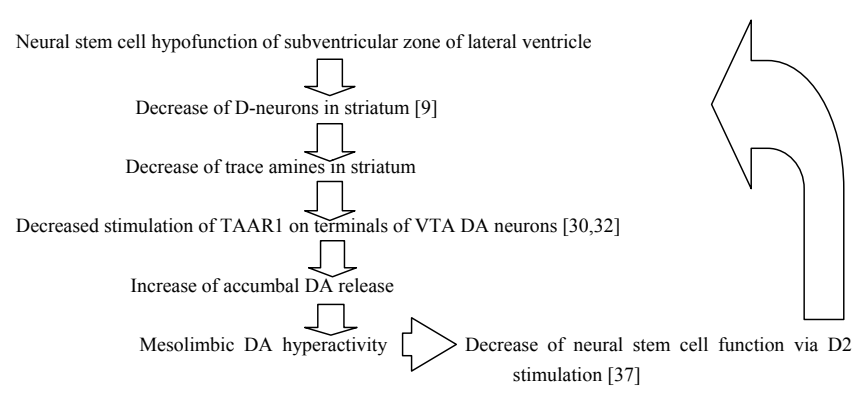

Figure 1: "D-cell hypothesis" of schizophrenia.
3. Watis L, Chen SH, Chua HC, Chong SA, Sim K (2008) Glutamatergic abnormalities of the thalamus in schizophrenia: a systematic review. J Neural Transm 115: 493-511.

4. Olbrich HM, Valerius G, Rüsch N, Buchert M, Thiel T, et al. (2008) Frontolimbic glutamate alterations in first episode schizophrenia: evidence from a magnetic resonance spectroscopy study. World J Biol Psychiatry 9: 59-63.

5. Christison GW, Casanova MF, Weinberger DR, Rawlings R, Kleinman JE (1989) A quantitative investigation of hippocampal pyramidal cell size, shape and variability of orientation in schizophrenia. Arch Gen Psychiatry 46: 10271032.

6. McGlashan TH, Hoffman RE (2000) Schizophrenia as a disorder of developmentally reduced synaptic connectivity. Arch Gen Psychiatry 57: 637 648.

7. Duan X, Chang JH, Ge S, Faulkner RL, Kim JY, et al. (2007) Disrupted-InSchizophrenia 1 regulates integration of newly generated neurons in the adult brain. Cell 130: 1146-1158.

8. Reif A, Fritzen S, Finger M, Strobel A, Lauer M, et al. (2006) Neural stem cell proliferation is decreased in schizophrenia, but not in depression. Mol Psychiatry 11: 514-522.

9. Ikemoto K, Nishimura A, Oda T, Nagatsu I, Nishi K (2003) Number of striata D-neurons is reduced in autopsy brains of schizophrenics. Leg Med (Tokyo) Suppl 1: S221-S224.

10. Jaeger CB, Teitelman G, Joh TH, Albert VR, Park DH, et al. (1983) Some neurons of the rat central nervous system contain aromatic-L-amino-acid decarboxylase but not monoamines. Science 219: 1233-1235.

11. Boulton AA (1974) Amines and theories in psychiatry. The Lancet 304: 52-53.

12. Boulton AA, Juorio AV (1979) The tyramines: are they involved in the psychoses? Biol Psychiatry 14: 413-419.

13. Komori K, Fujii T, Karasawa N, Yamada K, Ikuko N (1991) Some neurons of the mouse cortex and caudo-putamen contain aromatic L-amino acid decarboxylase but not monoamines. Acta Histochem Cytochem 24: 571-577.

14. Jaeger CB, Ruggiero DA, Albert V R, Joh TH, Reis DJ (1984) Immunocytochemical localization of aromatic-L-amino acid decarboxylase, in Handbook of Chemical Neuroanatomy. Classical Transmitters in the CNS, Part I. (Vol 2), Elsevier, Amsterdam 387-408.

15. Jaeger CB, Ruggiero DA, Albert VR, Park DH, Joh TH, et al. (1984) Aromatic L-amino acid decarboxylase in the rat brain: Immunocytochemical localization in neurons of the rat brain stem. Neuroscience 11: 691-713.

16. Tashiro $Y$, Kaneko T, Sugimoto $T$, Nagatsu I, Kikuchi H, et al. (1989) Striatal neurons with aromatic L-amino acid decarboxylase-like immunoreactivity in the rat. Neurosci Lett 100: 29-34.

17. Mura A, Linder JC, Young SJ, Groves PM (2000) Striatal cells containing aromatic L-amino acid decarboxylase: an immunohistochemical comparison with other classes of striatal neurons. Neuroscience 98: 501-511.

18. Ikemoto K, Kitahama K, Jouvet A, Arai R, Nishimura A, et al. (1997) Demonstration of $L$-dopa decarboxylating neurons specific to human striatum. Neurosci Lett 232: 111-114.

19. Ikemoto K, Nagatsu I, Kitahama K, Jouvet A, Nishimura A, et al. (1998) A dopamine-synthesizing cell group demonstrated in the human basal forebrain by dual labeling immunohistochemical technique of tyrosine hydroxylase and aromatic L-amino acid decarboxylase. Neurosci Lett 243: 129-132.

20. Kitahama K, Ikemoto K, Jouvet A, Nagatsu I, Sakamoto N, et al. (1998) Aromatic L-amino acid decarboxylase and tyrosine hydroxylase immunohistochemistry in the adult human hypothalamus. J Chem Neuroanat 16: 43-55.

21. Kitahama K, Ikemoto K, Jouvet A, Araneda S, Nagatsu I, et al. (2009) Aromatic L-amino acid decarboxylase-immunoreactive structures in human midbrain pons, and medulla. J Chem Neuroanat 38: 130-140.

22. Ikemoto K (2004) Significance of human striatal D-neurons: implications in neuropsychiatric functions. Prog Neuropsychopharmacol Biol Psychiatry 28 429-434.

23. Bunzow JR, Sonders MS, Arttamangkul S, Harrison LM, Zhang G, et al. (2001) Amphetamine, 3,4-methylenedioxymethamphetamine, lysergic acid diethylamide, and metabolites of the catecholamine neurotransmitters are agonists of a rat trace amine receptor. Mol Pharmacol 60: 1181-1188. 
Citation: Ikemoto K (2012) Are D-Neurons and Trace Amine-Associated Receptor, Type 1 Involved in Mesolimbic Dopamine Hyperactivity of Schizophrenia? Med chem 2: 038-040. doi:10.4172/2161-0444.1000111

24. Borowsky B, Adham N, Jones KA, Raddatz R, Artymyshyn R, et al. (2001) Trace amines: identification of a family of mammalian $G$ protein-coupled receptors. Proc Natl Acad Sci USA 98: 8966-8971.

25. Miller GM (2011) The emerging role of trace amine-associated receptor 1 in the functional regulation of monoamine transporters and dopaminergic activity. J Neurochem 116: 164-176.

26. Xie Z, Miller GM (2007) Trace amine-associated receptor 1 is a modulator of the dopamine transporter. J Pharmacol Exp Ther 321: 128-136.

27. Xie Z, Miller GM (2009) Trace amine-associated receptor 1 as a monoaminergic modulator in brain. Biochem Pharmacol 78: 1095-1104.

28. Lindemann L, Meyer CA, Jeanneau K, Bradaia A, Ozmen L, et al. (2008) Trace amine-associated receptor 1 modulates dopaminergic activity. J Pharmacol Exp Ther 324: 948-956

29. Zucchi R, Chiellini G, Scanlan TS, Grandy DK (2006) Trace amine-associated receptors and their ligands. Br J Pharmacol 149: 967-978.

30. Bradaia A, Trube G, Stalder H, Norcross RD, Ozmen L, et al. (2009) The selective antagonist EPPTB reveals TAAR1-mediated regulatory mechanisms in dopaminergic neurons of the mesolimbic system. Proc Natl Acad Sci USA 106: 20081-20086.

31. Revel FG, Moreau JL, Gainetdinov RR, Bradaia A, Sotnikova TD, et al. (2011) TAAR1 activation modulates monoaminergic neurotransmission, preventing hyperdopaminergic and hypoglutamatergic activity. Proc Natl Acad Sci USA 108: $8485-8490$

32. Panas HN, Lynch LJ, Vallender EJ, Xie Z, Chen GL, et al. (2010) Norma thermoregulatory responses to 3-iodothyronamine, trace amines and amphetamine-like psychostimulants in trace amine associated receptor 1 knockout mice. J Neurosci Res 88: 1962-1969.

33. Wolinsky TD, Swanson CJ, Smith KE, Zhong H, Borowsky B, et al. (2007) The Trace Amine 1 receptor knockout mouse: an animal model with relevance to schizophrenia. Genes Brain Behav 6: 628-639.

34. Ikemoto K (2008) Striatal D-neurons: in new viewpoints for neuropsychiatric research using post-mortem brains. Fukushima J Med Sci 54: 1-3.

35. Degreef G, Ashtari M, Bogerts B, Bilder RM, Jody DN, et al. (1992) Volumes of ventricular system subdivisions measured from magnetic resonance images in first-episode schizophrenic patients. Arch Gen Psychiatry 49: 531-537.

36. Horga G, Bernacer J, Dusi N, Entis J, Chu K, et al. (2011) Correlations between ventricular enlargement and gray and white matter volumes of cortex, thalamus, striatum, and internal capsule in schizophrenia. Eur Arch Psychiatry Clin Neurosci 261: 467-476.

37. Kippin TE, Kapur S, van der Kooy D (2005) Dopamine specifically inhibits forebrain neural stem cell proliferation, suggesting a novel effect of antipsychotic drugs. J Neurosci 25: 5815-5823. 